\title{
Comment
}

\section{Are Humans the Most Intelligent Species?}

\author{
Robert P. Erickson
}

Departments of Neurobiology, and Psychology and Neurosciences, Duke University, Durham, NC 27713, USA; E-Mail: eric@psych.duke.edu; Tel.: +1-919-572-9101

Received: 11 July 2014; in revised form: 9 September 2014 / Accepted: 10 September 2014 /

Published: 22 September 2014

\begin{abstract}
Hunt and Jaeggi [1] nicely summarize the point that within the academic field of intelligence, we do not have a commonly understandable definition of what intelligence is. Still the term is used extensively and with consensus to the effect that humans are the most intelligent species. An example is given of this problem, and a definition and solution are suggested.
\end{abstract}

Keywords: intelligence; definition of intelligence; species differences

We all understand that we are the most intelligent species; case closed. But the logic by which we come to that conclusion is not very intelligent. In this logic the first assumption is that we are the most intelligent, and then we accept that conclusion as valid in that no other species does what we do as well as we do.

But it is contrary to scientific method to assume an idea is true when we should be trying to define it and its implications so that we can test it. Rating other species' intelligence on how well they can do what we can do is illogical in that we begin by assuming our conclusion. With this standard, can humans determine the relative intelligence of ducks and dogs by comparing how well they can do what we can do?

Human's logical format is that "No other species can do better than a human what a human does, so humans are the most intelligent". Ducks can't write poetry. But put into its uncluttered format, humans' logic is that "If no other species can do better than species A what species A does, then species A is the most intelligent". Back to normal verbiage, "No other species can do better than a duck what a duck does, so ducks are the most intelligent".

If unbiased aliens came to determine which species is the most intelligent, might in their ignorance first test ducks. They would find that no other species could do what ducks do as well as that ducks do. 
Humans would fail as ducks; they cannot swim under water to catch food in their beaks, nor can they fly etc. (Humans can build airplanes, but they themselves cannot fly).

And in pointing out that in comparison with other species we have larger or more developed brains, or greater brain mass compared to our body mass, we lose sight of the fact that while anatomy and intelligence must be related, they are not the same topic; brain biology is not intelligence. We should not neglect the fact that porpoises, blue whales and elephants have larger brains than we, our advanced prefrontal evolution does not override the possible greater evolution of other parts of other species' brains, and that some animals, such as the rhesus, have a greater brain/body mass ratio than we. But we still use neuroanatomical data to support the idea that we are the most intelligent. Current expositions on this issue [e.g. 2,3,4] might usefully reach a wider audience, including neurobiology.

Using the term "intelligence" to compare individuals within a species, such as humans, is not the same topic as comparing species. To compare me to my brother, and then me to a duck, only provides confusion. Most species now are doing quite well as required by evolution; in this way the various species may be rated as similarly quite intelligent, and the individuals that carry forth their species may be rated as quite intelligent within the species. It is not clear that the human species could get a higher rating than other species. And most other current species have existed longer than humans.

It is proposed that the term "intelligence" would better be used for intra-species differences, comparing ducks with other ducks and individual humans with others, than for inter-species differences, comparing ducks with humans. These are different topics, and different terms should be used. In this view, "intelligence" would best be used only for comparisons within a species.

A term might be developed to compare various species' on their ability to survive and evolve. This would be something like "species intelligence". And an inclusive definition of "intelligence" to cover both inter- and intra-species differences might be developed. But to use the same term for both of these different topics would confuse the issues. Why should such an inclusive term be developed?

Perhaps the value of comparing the intelligence of different species should be questioned. Of what utility is such a comparison?

In conclusion, individuals within a species may be rated on how well they perform the job of being a successful member of that species, and the term of "intelligence" is well used for this rating. Various species might be compared on how well they are performing the task of survival and evolution. But these are not the same topics and should not be subsumed under the same rubric, "intelligence".

\section{Conflicts of Interest}

The author declares no conflict of interest.

\section{References}

1. Hunt, E.; Jaeggi, S.M. Challenges for Research on Intelligence: Commentary. J. Intell. 2013, 1, 36-54.

2. Barton, R.A.; Venditti, C. Human frontal lobes are not relatively large. Proc. Natl. Acad. Sci. USA 2013, 110, 9001-9006.

3. Herculano-Houzel, S. The remarkable, yet not extraordinary, human brain as a scaled-up primate brain and its associated cost. Proc. Natl. Acad. Sci. USA 2012, 109 (Suppl. 1), 10661-10668. 
4. Parvizi, J. Corticocentric myopia: Old bias in new cognitive sciences. Trends Cogn. Sci. 2009, 13, 354-359, doi:10.1016/j.tics.2009.04.008.

(C) 2014 by the authors; licensee MDPI, Basel, Switzerland. This article is an open access article distributed under the terms and conditions of the Creative Commons Attribution license (http://creativecommons.org/licenses/by/3.0/). 